\title{
Los antinewtonianos y la difusión de la ciencia newtoniana en la Nueva España del siglo XVIII.
}

\author{
Anti-newtonians, newtonian science spread out in 18th century \\ New Spain.
}

Esta obra está bajo una Licencia Creative Commons Atribución 4.0 Internacional. DOI: $10.32870 /$ sincronia.axxiii.n75.6a19

\section{Juan Manuel Espinosa Sánchez}

División de Ciencias Políticas y Humanidades

Universidad de Quintana Roo

newtonopticks@yahoo.com.mx

(MÉXICO)

Recibido: 07/09/2018

Revisado: $22 / 10 / 2018$

Aprobado: 07/11/2018

\section{RESUMEN}

Es importante mencionar que existen estudios encaminados a la historia de la ciencia en la Nueva España, relacionados con el desarrollo de la física, específicamente de la obra de Isaac Newton. Pero aún faltan trabajos para explicar quiénes eran los opositores de la mecánica newtoniana en suelo novohispano, quienes serían los defensores de Descartes, de las Sagradas Escrituras y de Aristóteles, entre otros.

Nuestro escrito va encaminado a analizar a los antinewtonianos, que son aquellos personajes que no están acorde con la postura de la ciencia newtoniana en la explicación de la naturaleza.

Palabras clave: Antinewtoniano. Jesuitas. Anticopernicanismo. Filosofía mecanicista cartesiana. Dinámica newtoniana. Descartes. Newton. 


\begin{abstract}
It is important to mention the existence of studies directed towards the history of science in New Spain related to the development of physics, specifically about the work of Isaac Newton. There is still a gap in research which would explain: who were the opponents to the Newtonian mechanics in New Spain territory, who would be the defenders of Descartes, the Holy Scriptures, and Aristotle, among others.

Our document is geared towards analyzing anti-Newtonians, those characters not in agreement with the Newtonian science stance about the explanation of nature.
\end{abstract}

Keywords: Anti-Newtonian. Jesuit. anti-Copernicanism. Cartesian mechanisist philosophy. Newtonian dynamics. Descartes. Newton.

\title{
Preámbulo
}

El presente trabajo forma parte de una investigación más amplia sobre el saber científico newtoniano y su difusión en suelo novohispano en el siglo XVIII. Un ejemplo de ello es el jesuita Francisco Xavier Clavijero en su obra pedagógica, llamado Curso de Filosofía (Navarro, 1948, pp. 146178), fue elaborada entre 1763-1766. Presenta una división aristotélica: la "phisica generalis" y la "phisica particularis". La primera parte está extraviada; en la segunda parte explicó los principios y propiedades de los cuerpos. Su texto es ecléctico por la diversidad de teorías científicas que empleó en la explicación de la naturaleza. En ella Clavijero critica a Ptolomeo, así como a Copérnico y acepta la hipótesis geocéntrica de Brahe; concibe a Galileo como defensor de la tesis heliostática en la comprensión del Sistema Solar y explica la teoría gravitacional de Newton. Hizo alusión a las teorías de Kepler, Deschales, Galileo, Newton y Copérnico para explicar las manchas solares. (Clavijero, 1995, pp. 62-101)

El jesuita Clavijero al igual que su compañero de la misma orden, Alegre, expuso en su Cursus (Navarro, 1948, pp. 146-178), la teoría gravitacional, pero de manera lacónica. No da una explicación de su aplicación en el Sistema Solar. Mientras que para ser newtoniano primero se debe 
aceptar a Copérnico, por el orden que les da a los planetas al girar en torno al Sol, Clavijero aceptó el modelo de Brahe que se apega a las Sagradas Escrituras. Clavijero es un antinewtoniano y padece un atraso teórico en la comprensión del macrocosmos. Los antinewtonianos se opusieron a la "ciencia newtoniana" porque los Principia de Newton, según se argumentaba, no pasaba de ser una obra abstracta, poco inteligible, oscura y misteriosa. Algunos críticos de la física newtoniana fueron el jesuita Rudjer Boscovich, George Berkeley, John Brooke, John Hutchinson y Samuel Taylor, entre otros. (Cantor, 1990, pp. 203-221).

Los jesuitas fueron los introductores de la enseñanza de la nueva física, la newtoniana, pero con el afán de criticarla y rechazarla. En este punto se da un consenso entre los jesuitas y es cuando existe una interlocución entre ellos y se llega a un acuerdo y conforme a nuestras fuentes primarias en sus obras pedagógicas aceptan a Brahe y Descartes. Los jesuitas son antinewtonianos porque rechazan los postulados de Newton y aceptan la filosofía cartesiana (Navarro, 1983, pp. 66-129; Navarro, 1948, pp. 146-178; Feyjóo, 1742a, pp. 294-308; Feyjóo, 1742b, pp. 145-149).

\section{Antecedentes jesuitas y el cosmos}

En esta parte de nuestro respectivo trabajo, no se dará una argumentación histórica pedagógica de la labor de los jesuitas en la Nueva España (Aizpuru, 1989, p. 247), sino, más bien como difusores del conocimiento científico en las aulas y al colaborar en las labores científicas del Estado virreinal. La erección de la orden que encabezó San Ignacio del Loyola tuvo fines ideológicos de la Contrarreforma, (Acerito, 1994, pp. 25-30) para contrarrestar la reforma protestante. Sin duda al inició de su labor educativa, la orden jesuita se preocupó por la enseñanza de la matemática (Rugiu, 1995, p. 249) como fin social en la preparación de los ingenieros civiles.

En la Nueva España, no fue la excepción con la tradición de los estudios en la matemática y su aplicación en problemas reales, tal fue el caso del jesuita Juan López Arbaisa natural de Durango, nació en 1556, ingresó a la compañía de Jesús en 1579 y obtuvo sus votos en 1571, a la edad de 28 años viajó a la ciudad de México. López Arbaisa construyó la cúpula de gran clave, lo cual fue una innovación en la 
arquitectura teórica y práctica, además de ser el arquitecto del templo de San Pedro y San Pablo de la ciudad de México y de la iglesia de la compañía en Puebla. En el año de 1607, por las fuertes lluvias se desbordó el agua de la laguna de Texcoco e inundó las acequias y las calles, por sus conocimientos científicos fue seleccionado por el cabildo civil para dar una solución al problema de las inundaciones de la ciudad de México (Soriano, 1994, pp. 60-62). López Arbaisa falleció en la capital de la Nueva España en 1612.

Otro aspecto interesante fue el incremento de obras científicas en las bibliotecas (García, 1990, pp. 101-102; Trabulse, 1994b, pp. 35-37) de los diversos colegios de las distintas órdenes religiosas en la Nueva España, en este sentido, gran parte de los clérigos eran arquitectos en la construcción de sus templos y conventos, por lo que hubo una dualidad en la estructura cognoscitiva del conocimiento novohispano, en la práctica hacían gala de su erudición matemática, botánica, astronómica, cartográfica, entre otras. Mientras en el aspecto teórico de la ciencia eran metacientíficos al hacer usó de la Biblia, para explicar a la naturaleza.

Al iniciar el siglo XVIII, los egresados de los colegios jesuitas, que posteriormente culminaron sus estudios universitarios, por las fuentes gran parte de ellos llevaron la batuta en la cultura novohispana, como fue el caso de José Antonio Villerías y Roelas nació en la ciudad de México el 29 de mayo de 1695, estudió en el Colegio Máximo de San Pedro y San Pablo y más adelante jurisprudencia en la Universidad de México. Además, participó en actos y certámenes literarios entre 1714 y 1724, Villerías redactó varias obras: La Máscara, en 1728, una poesía sobre la virgen de Guadalupe en 1724, el Llanto de las estrellas en 1725, y el Cantar de los Cantares en el mismo año que la anterior, él falleció el 12 de agosto de 1728.

El Llanto de las Estrellas es una obra dedicada a Luis I, rey de España quién permaneció en el trono entre enero y agosto de 1725 y Villerías lo relacionó con el Sol, porque el astro solar es el centro del universo con movimiento y es fuente de la luz. Con esto, Villerías hizo una alegoría del rey. Estos temas herméticos fueron hechos por Fisino, Campanella, Bruno, Cusa, Mirandola y Copérnico (Romero, 1991, pp. 12-224). La citada obra está impregnada de la dualidad de la sabiduría, que es la ciencia, en 
lo particular la teoría astronómica de Copérnico y la metafísica de Aristóteles. Pero estuvo el peso ideológico de la Iglesia, que hizo establecer sus dogmas de la fe antes que la ciencia, para explicar la naturaleza, por lo tanto, la mencionada obra es un fiel reflejo del anticopernicanismo, pero habló de la Vía Láctea, como una muestra de sus conocimientos astronómicos.

Juan Antonio de Mendoza y González estudió con los jesuitas en San Ildefonso en Puebla, fue cura y juez eclesiástico de los partidos de Tepecuacuilo y Tampamolón. Además, fue contador de la catedral de Puebla y notario de la Inquisición y agrimensor, se desconoce si estudió en la Universidad de México, redactó el Método para corregir Reloxes, el Modo para desagüar Minas, en esta última obra, Mendoza y González empleó la filosofía mecanicista cartesiana y el hermetismo de Kircher, y también citó a Schott, Lana Terzi, Mersenne, Rohaut, Cavalieri y Dechales. Es un texto con un lenguaje filosóficohermético. Este tipo de léxico perduró en la Nueva España en los inicios de la centuria dieciochesca (Trabulse, 1982, pp. 189-195).

Mendoza y González también escribieron sobre astronomía su libro la Spherografía de la obscuración de la Tierra en el Eclypse de Sol de 22 de marzo de 1727. Méthodo de observarle y de corregir los reloxes. En esta obra analizó, la trayectoria de la sombra proyectada por la Luna y elaboró un mapa astronómico, en donde representó a California como una isla. Sobre este punto cabe recordar, que Kino, en 1702 demostró que California es una península, pero el propósito de Mendoza era determinar los puntos cartográficos de la América Hispánica y las Antillas (Trabulse, 1994a, p. 90).

El historiador Elías Trabulse (1992) hizo una división de las diferentes etapas de la historia de la ciencia en México. En ello determinó que entre 1680 a 1750 hubo dos corrientes filosóficas en la cultura novohispana, la hermética y la organicista. (Mayer, 1998, p. 81-92.) La primera se desarrolló en los escritos de los matemáticos, conjuntamente con la filosofía mecanicista cartesiana, como el caso Sigüenza y Mendoza. La segunda, la organicista, se difundió en la Real y Pontificia Universidad de México (García, 2006, pp. 207-208). En este período oscuro no se han hallado escritos científicos de los maestros universitarios ligados principalmente a la cátedra de Astrología. Se puede dar el nombre y fechas de ellos, pero me parece muy ocioso dado que desconozco algún escrito de dichos profesores 
después de jubilarse Sigüenza a finales del siglo XVII, hasta 1765, año que ocupo la materia como profesor Velázquez de León.

Mendoza, al redactar el funcionamiento teórico de una bomba para desaguar las minas, tuvo el conocimiento de la necesidad de construir un artefacto para el beneficio de la minería, ya que los gastos que eran muy elevados para tal maniobra, también consideró el levantamiento de un plano de una parte del continente americano basándose en las observaciones que hizo de un eclipse para con este método calcular los puntos cartográficos de las colonias españolas. (Trabulse, 1982, pp. 189-195)

\section{Los jesuitas antinewtonianos y la difusión. De newton en la ilustración novohispana}

En estas cinco décadas del siglo XVIII, perduró la filosofía mecanicista cartesiana, aunque en Europa continental se estaba abriendo paso la dinámica newtoniana, cuyos resultados en la experimentación comprobaron las diversas teorías de Newton como la propagación de la luz en línea recta, el achatamiento de la Tierra en los polos, la explicación del macrocosmos con la teoría gravitacional, entre otras, y con el tiempo se fue rechazando la metafísica cartesiana, dado que ésta no contradecía los cánones religiosos del catolicismo.

Un ejemplo de ello lo menciona el propio Descartes en su obra los Principios de la Filosofía (1995) donde incluso rechaza los postulados matemáticos para explicar a la naturaleza y se acerca a Dios como el creador del Mundo como se ve a continuación:

También dudamos de todas las otras cosas que nos han parecido muy ciertas en otro momento, incluso de las demostraciones de la matemática y de sus principios... dado que hay hombres que, razonando sobre tales materias, se han equivocado. Pero, hemos de dudar principalmente porque hemos oído decir que Dios (Descartes, 1995, p. 24).

Sin lugar a dudas este conocimiento fue apoyado por instrumentos científicos mejor elaborados, para tener una mejor observación de los fenómenos celestes, determinando así una buena cronometría de estos sucesos para tener un progreso en la astronomía teórica y observacional, con la ayuda del telescopio newtoniano catadióptrico (construido con una lente y un espejo con el fin de eliminar la aberración acromática producida por los lentes construidos con el método galileano y gregoriano). Los 
constructores Short y Dollond fabricaron en grandes cantidades el telescopio newtoniano para los astrónomos europeos, incluso estos instrumentos llegaron a ser utilizados por los mejores astrónomos novohispanos del siglo XVIII: Velázquez de León y León y Gama.

Pero sin duda el logro que revolucionó a la matemática fue el método de fluxiones, que conocemos en nuestros días como el cálculo diferencial e integral, aunque la polémica entre Newton y Leibnitz no viene al caso, dado, que ellos por dos métodos diferentes, lograron el avance de la matemática. Este descubrimiento sin precedentes fue de gran ayuda para explicar en teoría el sistema del mundo newtoniano, rompiendo con las tautologías del hermetismo y la filosofía mecanicista cartesiana y de paso con la concepción teológica cristiana del mundo.

Con la dinámica newtoniana se explicaron en el siglo XVIII, los movimientos de los cuerpos celestes, no sólo de nuestro sistema planetario sino también de los cometas, de las estrellas dobles, del movimiento de nuestra galaxia, es decir, en teoría y práctica fue el progreso de la ciencia. Es un hecho que esta gnoseología científica en su momento tuvo logros significativos, porque contradecía los dogmas de la fe y al jesuita Descartes. Por lo tanto, la centuria dieciochesca es el siglo de las luces, el siglo de la razón y el siglo de la difusión, el progreso y el desarrollo de una nueva metodología para explicar el universo: la física newtoniana. Esta será extendida por sus difusores desde Inglaterra a la Europa Continental (la católica y la protestante) y al continente americano, desde las colonias inglesas del norte de América hasta la Patagonia, siendo sus principales difusores en la Nueva España los colegios jesuitas, ellos son la semilla para que en otros colegios religiosos y en la Universidad de México deba ser enseñada antes que en los planteles erigidos por el Estado español al concluir el último tercio del siglo XVIII.

Los jesuitas, en la segunda mitad de la mencionada centuria, introdujeron la enseñanza de la nueva física: la newtoniana. Los escritos elaborados en latín estaban impregnados de eclecticismo, es decir, varias teorías para explicar el cosmos. Estos textos eran utilizados por los profesores jesuitas en la materia de Filosofía. Entre los más destacados están Salvador Dávila, quien disertó sobre las teorías de Leibnitz, Newton y Descartes. Agustín Castro expuso a Descartes y Newton. El jesuita Vallarta enseñó 
filosofía en Puebla en 1749, en su obra Juliani epistolae Ponciiad Christianum Philadelphum de Cunniculis Philosophics epistolae, publicado en Toscana en 1779, que fue un ataque a la teología cristiana, además, argumentó sobre la metafísica cartesiana, así como sobre la filosofía de Gassendi, Copérnico y la física de Newton, que contradecían las sagradas escrituras (González Casanova, 1948, pp. 130-165), pero principalmente esta última, la cual considera que las partículas de la materia son el principio de la estructura de los seres y de los objetos, es la teoría más peligrosa junto a su sistema del mundo por lo que fue considerada como una doctrina hereje, ya que, Newton explicó sobre el origen del mundo. Una de sus leyes, la teoría gravitacional, argumenta el movimiento del sistema solar, demostrando que esta fuerza varía inversamente en el cuadrado de la distancia entre la Tierra y la Luna, posteriormente Newton la extendió al astro solar sobre los demás planetas y estos sobre sus satélites, llamando a esta fuerza gravedad, y con la aplicación de la matemática, el experimento y la observación crítica quedó escrita en su obra los Principia (Cohen, 1989, pp. 245-246). Con estos nuevos métodos contradice Newton a la Biblia, sin embargo, la materia de Filosofía en los colegios jesuitas fue el medio para la difusión de la física newtoniana (Casanova, 1948, pp. 130-165).

Diego José Abad enseñó filosofía en el Colegio Máximo de México entre los años de 1754 y 1756, redactó varias obras relacionadas a la ciencia un Compendio de Algebra, una Geografía Hidráulica y un Cursus Philosophicus. (Navarro, 1948, pp. 146-178).

Francisco Xavier Alegre enseño filosofía en la isla caribeña de Cuba y posiblemente en la ciudad de México, redactó un Cursus Philosophicus, (Archivo Histórico de la Biblioteca Nacional de Antropología e Historia, legajo 35, Segunda Serie [Papeles Sueltos], legajo 35, Documento 4, f.1r-1v.), otras de sus obras fueron los Elementorum geometriae, el Compendio de Bion y Sfnornio sobre los instrumentos matemáticos y el Tractatu de gnomica.

Francisco Xavier Clavijero es el jesuita al cual le dedicaremos más páginas, debido a que el Dr. Bernabé Navarro, antes de fallecer, tradujo del latín al español su Cursus Philosophicus y fue publicado posteriormente por la Universidad Michoacana. En esta obra donde Clavijero expuso varias teorías científicas para explicar la naturaleza, como las leyes de Galileo, Kepler, Copérnico, Descartes, Newton, 
entre otros, teniendo como premisa la enseñanza de estos temas científicos a la juventud novohispana, principalmente la macrofísica. (Clavijero, 1995, p.62, 76-78, 97-101.) Los cursos de Filosofía eran impartidos en los colegios jesuitas de la ciudad de México, el de San Ildefonso de Puebla, en Guadalajara, Valladolid, Pátzcuaro, Oaxaca, Guanajuato, Mérida, Querétaro y Zacatecas. Además, la orden jesuita sustentó cuatro cátedras de Teología en la Universidad de México en el siglo XVIII (Bravo, 1966, pp. 71-72).

El catedrático hacía gala de su erudición científica, durante la clase que impartía, así lo demuestran los textos que escribieron los jesuitas para tal fin.

Francisco Xavier Clavijero nació en Veracruz, el 9 de septiembre de 1731, posteriormente ingresó a la orden jesuita el 13 de febrero de 1748, (A.H.B.N.A.H., Fondo Jesuita, v.17, f.13-14), fue políglota; entre los idiomas que dominó están el hebreo, el griego, el francés, el portugués, el alemán, el inglés y el náhuatl.

Además, fue lector de Galileo, Kepler, Descartes, Gassendi, Losada, Tosca Purchot, Duhamel, Leibnitz, Newton y Sigüenza y Góngora (Rosales, 1988, p. 80). Clavijero enseñó Retórica en el Colegio Máximo y posteriormente en el Colegio de San Francisco Xavier en Puebla, y Filosofía en Valladolid y en Guadalajara, además de ser prefecto en San Ildefonso en la capital novohispana. Su libro pedagógico Cursus Philosophicus tiene una división aristotélica: la "physica generalis" y la "phisica particularis". La primera parte está extraviada, en la segunda parte explicó los principios y propiedades de los cuerpos naturales, su texto es ecléctico, por la diversidad de teorías científicas que empleó el autor para explicar el cosmos (Ronan, 1993, p. 76).

Antes de la expulsión de los jesuitas en 1767, por Real Cédula, Clavijero era conocido en Europa, principalmente en la península itálica, por su tesis De Universa Philosophia, que defendió en Valladolid (Navarro, 1948, p. 72). Su estancia cronológica en este lugar fue entre 1763-1766, en donde redactó su Cursus Philosophicus. Clavijero falleció el 2 de abril de 1787, en el destierro en Italia (residió en Ferrara y Bolonia), a partir de 1970, sus restos descansan en la rotonda de los hombres ilustres en la ciudad de México (Rosales, 1988, pp. 76 y 86). 
Clavijero en su Cursus explicó que el cosmos es infinito e increado, contradiciendo los cánones religiosos católicos en torno a la finitud y la creación del mundo por Dios (1.2-31 Gn. 2.2-3 La Santa Biblia, Yates, 1983, pp. 239-271). Posteriormente, acerca del sistema del mundo, argumentó y rechazó la teoría de Ptolomeo, criticó los postulados copernicanos y aceptó la hipótesis geocéntrica de Brahe. Más adelante, en la obra, Clavijero llegó a la siguiente conclusión: "El sistema copernicano no puede ser defendido como tesis 1.- porque la opinión acerca de la quietud del Sol y del movimiento de la Tierra parecen oponerse a las Sagradas Escrituras." (Clavijero, 1995, p. 62).

Al respecto Clavijero, al igual que los jesuitas del siglo XVII, enseñaron la teoría copernicana para criticarla y rechazarla en sus aulas, teniendo en cuenta que los jesuitas europeos no compartían la tesis copernicana difundida por Galileo, en razón de las polémicas del jesuita Cristóforo Scheiner contra Galileo en torno a las manchas solares entre 1610 a 1611, y posteriormente la del jesuita Orazio Grassi quien redactó la Disputatio astronomica de tribus cometis, para explicar la aparición de tres cometas en la bóveda celeste en 1619. Galileo escribió el Ensayador en donde argumentó estos fenómenos ópticos los cuales, para él, son semejantes a la aurora boreal o al arco iris, criticando además el conocimiento aristotélico. (Galilei, 1984b, p. 155). Clavijero hace mención de Galileo como defensor de la tesis heliostática copernicana (Copérnico, 1987, p. 33) y por tal motivo la Inquisición le siguió un proceso a Galileo por difundir y defender esta teoría, en 1633.

En relación del sistema del mundo, Clavijero aceptó el de Brahe, porque, la Tierra esta inmóvil en el centro del mundo y el Sol gira alrededor de ella misma (Clavijero, 1995, pp. 76-78). Además, Clavijero conoció el instrumento óptico para observar el macrocosmos: el telescopio y es de gran utilidad al visualizar y estudiar nuestra galaxia, es decir, la Vía Láctea, además de citar a Kepler al hacer referencias de las estrellas (Clavijero, 1995, p. 91).

En esta parte el propio Clavijero también tiene influencia cartesiana, dado que el propio Descartes rechazó la hipótesis copernicana del movimiento de la Tierra, tal y como lo menciona en su libro de los Principios de la Filosofía: 
Copérnico al atribuir movimiento a la Tierra, y que trataría que mis razones sobre este tema sean más verdaderas que las de Tycho, propondría aquí la hipótesis que parece ser la más simple de todas y, a la vez, la más apropiada de todas tanto para conocer los fenómenos como para indagar las causas naturales. $Y$, sin embargo, advierto que no pretendo que sea recibida como enteramente conforme a la verdad, sino solamente como una hipótesis o suposición que puede ser falsa (Descartes, 1995, p. 130).

Clavijero rechaza el postulado copernicano y acepta al de Tycho indudablemente también está acorde con Descartes en este argumento para no aceptar la postura de Copérnico en razón que contradice a las Sagradas Escritura y nuestro sabio jesuita está acorde con las posturas filosóficas de defender la fe, contra todo signo de heterodoxia científica que pueda mancillarla como se observa en los párrafos arriba señalados y es otra muestra de la influencia cartesiana en el mundo científico jesuita de la Nueva España en la época de la llustración.

Posteriormente Clavijero explicó: ¿Cuál es la naturaleza del Sol? En su disertación tercera mencionó:

$$
\begin{aligned}
& \text { Por que, [sic] si se observa el Sol con el telescopio, aparece inmediatamente no } \\
& \text { sólo aquel perenne movimiento y la agitación incesante de las partes, que de algún } \\
& \text { modo son cosas propias del fuego; si no que también cierto como torbellinos de } \\
& \text { llamas parecen brotar de la sustancia de aquel, los cuales en un cierto período } \\
& \text { determinado crecen, decrecen y a veces renacen. Esto mismo parece demostrase } \\
& \text { por el cuerpo solar (Clavijero, 1995, p. 98). }
\end{aligned}
$$

En esta descripción científica hecha por Clavijero se percibe la influencia cartesiana, en razón que Descartes explico en su obra Los Principios de la Filosofía, menciona lo siguiente: "Pensemos también que los cuerpos opacos que se ven sobre el Sol utilizando lentes de largo alcance y que se conocen como sus manchas, se mueven sobre su superficie... (y) exactamente todos los torbellinos que lo rodean, que la materia del primer elemento procedente del Sol," (Descartes, 1995, pp. 139 y 177). 
Además, Clavijero siendo jesuita conoció la polémica entre Scheiner y Galileo sobre las manchas solares, pero Clavijero además menciona que el Sol tiene movimiento, esta teoría fue expuesta por Kepler (1984, p. 148), descubierta la rotación solar por Galileo al estudiar las manchas solares (Galilei, 1984b, p. 154; Koyré, 1996).

Además, Clavijero rechazó la teoría gravitacional aludiendo que el Sol es pesado y no tiene por qué caer sobre la Tierra, por falta de demostraciones no se ha descubierto "si las cosas pesadas, llevadas al Cielo, deberían descender, a la Tierra." (Clavijero, 1995, p. 97).

Es un hecho que Clavijero no aceptó en parte la teoría gravitacional en razón de ser religioso y sustentar una explicación aristotélica, lo que implica un eclecticismo en su Cursus, pero se apoyó en esta teoría de Newton al explicar que las manchas solares no son cuerpos sólidos y que aparecen en el disco solar según Dechales y no de vapores terrestres y otros cuerpos interpuestos, además argumentó sobre el movimiento de la Tierra con la hipótesis copernicana (Clavijero, 1995, p. 99). El mismo Clavijero hace mención que observó al Sol con el telescopio y estableció su movimiento de rotación en "27 días, 12 horas y 21 minutos" (Clavijero, 1995, pp. 100-101).

En esta parte, Clavijero da una muestra de su erudición teórica y práctica, para establecer el período de la rotación del Sol , dando una respuesta acerca de la naturaleza de las manchas solares con apoyo en las teorías de Copérnico, Galileo, Kepler, Dechales y Newton, lo que confirmó la enseñanza elevada en los colegios jesuitas y del establecimiento de una comunidad científica; este tipo de educación tuvo como finalidad formar la capacidad intelectual de sus estudiantes y prepararlos para la vida académica universitaria, en razón de hacerlos críticos y dar una explicación científica del universo, en otras palabras preparaba a la juventud, para llegar a ser miembros de la compañía de Jesús.

\section{Conclusión}

También en la comunidad científica jesuita existió el consenso de la aceptación del sistema de Brahe durante los siglos XVII y XVIII, para no contradecir a las Sagradas Escrituras, pero es evidente que, en el siglo de las luces, la difusión de las teorías científicas, para explicar el cosmos, contradicen a la Biblia. 
Así lo demuestran los escritos hechos para la materia de Filosofía elaborados por los mismos jesuitas, entre 1749 a 1765 aproximadamente. Posteriormente el oratoriano Gamarra, en 1774, redactó un texto para tal fin. Ello es una muestra de la labor educativa de la ciencia en planteles religiosos. (Herrejón, 1982, p. 103 - 117).

Mientras que en los años de 1765 a 1774 la difusión de la ciencia se llevó a efecto en la Real y Pontificia Universidad, en la cátedra de Astrología y Matemática siendo sus profesores Joaquín Velázquez de León e Ignacio Bartolache. Si bien la historiografía no registra el progreso de la ciencia en la Universidad de México (Soto, 1995, pp. 96-100), es una intención de la presente tesis mostrar con fuentes de archivo que si hubo difusión científica en el periodo citado.

\section{Referencias:}

Archivo Histórico de la Biblioteca Nacional de Antropología e Historia. Ramo: Segunda Serie (Papeles Sueltos). Fondo Jesuita.

Acerito, G. C. (1994). "Los Jesuitas y la educación en la Nueva España y Campeche. 1572-1767". Cuadernos Culturales. 7 / 25-30.

Aizpuru, P. (1989). La Educación Popular de los Jesuitas. México: Universidad Iberoamericana.

Bravo, J. (1966). "Los jesuitas mexicanos del siglo XVIII y sus actividades en el campo de las ciencias." En: Bravo, J. Temas Históricos Diversos, (pp. 71-71). México: Jus.

Cantor, G. (1990). “Anti-Newton”. En: Fauvel- Robin, J. (ed.), Let Newtom Be! (pp. 303-221). Great Britain: Oxford University.

Clavijero, F. J. (1995). Física Particular. Edición facsimilar, Morelia, Michoacán: Universidad Michoacana de San Nicolás de Hidalgo.

Cohen, I. B. (1989). El Nacimiento de la Nueva Física. Madrid. España: Alianza.

Copérnico, N. (1987). Sobre las Revoluciones de los Orbes Celestes. Madrid. España: Tecnos.

Descartes, R. (1995). Los Principios de la Filosofía. Madrid. España: Alianza Universidad. 
Feyjóo, B. G. (1742a). Cartas Eruditas y Curiosas. T. IV. Madrid. España: Imp., de los Herederos de Francisco del Hierro.

Feyjóo, B. G. (1742b). Theatro Crítico Universal. T. III. Madrid. España: Imp., de los Herederos de Francisco del Hierro.

Galilei, G. (1984a). El Ensayador. Madrid. España: Sarpe.

Galilei, G. (1984b). Segunda Carta sobre la Historia y Demostraciones en torno a las Manchas Solares (1621). Madrid. España: Alianza.

García, A. R. (1990). Una Monarquía Criolla. La Provincia Agustina de México en el siglo XVII. México. Consejo Nacional para la Cultura y las Artes.

García, A. R. (2006). Monjas, Cortesanos y Plebeyos. La vida cotidiana en la época de Sor Juana, México, Taurus.

González, P. (1948). El Misoneísmo y la Modernidad Cristiana en el Siglo XVIII. México: El Colegio de México.

Herrejón, C. (1982). "Benito Díaz de Gamarra crítica sobre su física." En Humanistas Novohispanos de Michoacán. Morelia. Michoacán: Universidad Michoacana de San Nicolás de Hidalgo.

Kepler, J. (1984). Conversación con el Mensajero Sideral. Madrid. España: Alianza.

Kepler, J. (1992). El Secreto del Universo. Madrid. España: Alianza.

Koyré, A. (1996). Etudes Galiléenes. Paris, France: Hermann.

Mayer, L. (1998). “Ciencia, Planetas y Cometas. La Revolución Científica del Siglo XVII”. En von Wobeser, G. (Coord.), Cincuenta años de Investigación Histórica en México. México, I.I.I.H.UNAM- Universidad de Guanajuato.

Navarro, B. (1948). Introducción a la Filosofía Moderna en México. México. El Colegio de México.

Navarro, B. (1983). Cultura mexicana moderna en el siglo XVIII. México. Facultad de Filosofía y Letras-UNAM.

Romero, I. O. (1991). El Sueño Criollo. José Antonio Villerías Roelas (1695-1728). México. I.I.B.UNAM. 
Ronan, C. E. (1993). Francisco Xavier Clavijero, S.J. (1731-1787). Figura de la llustración Mexicana: su Vida y Obras. Guadalajara, Jalisco: Instituto Tecnológico y de Estudios Superiores de Occidente-Universidad de Guadalajara.

Rosales, A. M. (Comp.) (1988). Francisco Xavier Clavijero en la Ilustración Mexicana 1731-1787. México. El Colegio de México.

Rugiu, A. S. (1995). Historia Social de la Educación. De la Educación Antigua al Origen de la Educación Moderna. V. I. Morelia, Michoacán: Instituto Michoacano de Ciencia de la Educación.

Soriano, A. E. (1994). Los Jesuitas en la Puebla del Siglo XVI. Labor educadora y evangelizadora. El Colegio del Espíritu Santo, Hoy Universidad Autónoma de Puebla. La Verdadera Fecha de su Fundación. Puebla. Universidad Iberoamericana-Instituto Oriente.

Soto, D. (1995). "La Enseñanza en la Universidad de América Colonial. Estudio Historiográfico". En: Arango, D. S.; Puig-Samper, M.A. y Arboleda, L. C. (Eds.). La Ilustración en América Colonial. Madrid Doce Calles - CSIC, España: Colciencias,

Trabulse, E. (1982). El Círculo Roto. Estudios Históricos sobre la Ciencia en México. México: Secretaría de Educación Pública-Fondo de Cultura Económica.

Trabulse, E. (1994a). Ciencia y Tecnología en el Nuevo Mundo. México. El Colegio de México-Fondo de Cultura Económica.

Trabulse, E. (1994b). Los Orígenes de la Ciencia Moderna en México (1630-1680). México. Fondo de Cultura Económica.

Yates, F. A. (1983). Giordano Bruno y la Tradición Hermética. Barcelona. España: Ariel. 